\title{
ADOLESCENT SEXUAL HEALTH
}

\section{Herpes simplex virus type 1 infection: a sexually transmitted infection of adolescence?}

\author{
F M Cowan, A Copas, A M Johnson, R Ashley, L Corey, A Mindel
}

Sex Transm Infect 2002;78:346-348

Objectives: To examine the factors associated with antibodies to herpes simplex virus type 1 (HSV-1).

Design: Cross sectional study with HSV-1 antibody testing performed by University of Washington western blot assay.

Setting: Central London STD clinic (1990-1) and central London blood donation centre (1992).

Participants: Representative sample of 869 new and rebooked GUM clinic attenders and 1494 consecutive blood donors.

Results: The prevalence of HSV-1 antibody among clinic attenders was $60.4 \%(95 \% \mathrm{Cl} 57.0$ to 63.7$)$ and among donors was $46.1 \%(95 \% \mathrm{Cl} 43.5$ to 48.7$)$. HSV-1 antibody was independently associated with increasing age in both populations $(p<0.001)$. Among clinic attenders, HSV-1 was less common among heterosexual men than women and homosexual men $(p<0.005)$, and was more common among black people $(p=0.001)$ and those of lower socioeconomic status $(p=0.05)$. Among blood donors, being single rather than married was independently associated with HSV-1 infection $(p=0.03)$. Early age at first intercourse was strongly associated with presence of HSV-1 in both populations. The adjusted odds of HSV-1 among GUM clinic attenders was $0.37195 \% \mathrm{Cl}$ 0.21 to 0.65$)$ for someone aged 20 at first intercourse compared with someone aged $\leqslant 15$. Among blood donors, those aged 20 had an adjusted odds of 0.64 (95\% Cl 0.39 to 1.05 ) compared with someone aged 15 . HSV-1 was not associated with increasing number of lifetime partners after adjustment for other factors.

Conclusions: Genital herpes due to HSV-l antibody is increasing in the United Kingdom, particularly among young people. In this study we found that HSV-1 was strongly associated with early age of first sexual intercourse, which may reflect the sexual practices of people initiating sex in this age group.

$\mathrm{H}$ erpes simplex virus type 1 (HSV- 1 ) infection is a common viral illness, which classically causes oro-labial herpes (cold sores). Serological studies from the 1940s indicate that infection with HSV was almost universal in adulthood. ${ }^{1}$ However by the 1970s only $50 \%$ of adults were infected. ${ }^{1}$ This decrease has been attributed to the improvement in socioeconomic circumstances that occurred over that time. When type specific HSV serological tests first became available, Nahmias conducted a global survey of HSV-l and HSV-2 infection and concluded that HSV-1 may be a useful marker of temporal change in sociological patterns within communities. $^{2}$ A recent serological survey of over 5000 samples collected as part of the UK PHLS serosurveillance programme showed that the rate of infection among 10-14 year olds had dropped from $34 \%$ in $1986-7$ to $24 \%$ in $1994-5 .^{3}$ The majority of young people are therefore HSV-1 naive at the onset of sexual activity. In addition, descriptive studies of genital herpes from the United Kingdom have noted that the proportion of infection due to HSV-1 rather than HSV-2 is increasing, particularly in young people ${ }^{4-6}$; however, the extent of sexual acquisition of HSV-l at a population level is unknown.

We report the results of a serological survey of antibodies to HSV performed among attenders at a department of genitourinary medicine (GUM) and donors attending a blood donation centre in central London, which examines the demographic and behavioural factors associated with HSV-I infection.

\section{METHODS}

Between November 1990 and December 1991, 869 consecutive GUM clinic patients attending a representative sample of clinics were invited to participate in the study, as were 1494 consecutive blood donors between February and April 1992. All participants had a blood sample taken for antibodies to HSV and self completed a questionnaire, which collected information on demographic and behavioural characteristics as well as on symptoms/history of herpes infection. Results on HSV-2 seroprevalence and symptoms of herpes infection have been published elsewhere. ${ }^{78}$

Blood samples were tested for herpes simplex virus antibody at University of Washington by western blot ${ }^{9}$ which is sensitive and specific for identifying patients with past herpes simplex virus type 1 and herpes simplex virus type 2 or co-infected with both agents.

Statistical analysis was undertaken using STATA 6.0. The unadjusted odds of HSV-1 were calculated for sociodemographic and behavioural factors. The adjusted odds were calculated adjusting for all other factors. This complete case analysis was based on 759 (STI clinic attenders), and 1144 (blood donors) participants respectively. In order to examine the extent to which sexual behaviour is associated with HSV-1 acquisition, the calculation of adjusted odds of HSV-1 only included individuals who had ever had sex. In order to separate the effects of age and age at first sexual intercourse, a subset of the data was reanalysed (individuals $>25$ years who had had sex before age 25). These results are not presented here, but this analysis did not substantially change the results.

\section{RESULTS}

The response rate was $98 \%$ among eligible participants at both sites. The demographic and behavioural characteristics of the populations are shown in table 1. Sixty four per cent of clinic attenders were single, $84.6 \%$ were white and $76.9 \%$ were in social class I, II, or III. Thirty five per cent of male and $51 \%$ of female donors were single and overall $94 \%$ were white. Information on occupation was not collected from blood donors.

The prevalence of antibody to HSV-l among clinic attenders was $60.4 \%$ (95\% CI 57.0 to 63.7 ) and among donors was $46.1 \%$ (95\% CI 43.5 to 48.7 ). The demographic and behavioural factors associated with presence of antibody to HSV-l are shown 


\begin{tabular}{|c|c|c|}
\hline \multirow[b]{2}{*}{ Demographic characteristics } & \multirow{2}{*}{$\begin{array}{l}\text { GUM attenders } \\
(n=836) \\
\%(\mathrm{No})\end{array}$} & \multirow{2}{*}{$\begin{array}{l}\begin{array}{l}\text { Blood donors } \\
(n=1446)\end{array} \\
\%(\mathrm{No})\end{array}$} \\
\hline & & \\
\hline Sex & & $(n=1411)$ \\
\hline Female & & $48(678)$ \\
\hline Male & & 52 (733) \\
\hline Sex/orientation & \multicolumn{2}{|l|}{$(n=827)$} \\
\hline Female & \multicolumn{2}{|l|}{$41(343)$} \\
\hline Male heterosexual & \multicolumn{2}{|l|}{$35(291)$} \\
\hline Male homosexual & \multicolumn{2}{|l|}{23 (193) } \\
\hline Age & $(n=827)$ & $(n=1412)$ \\
\hline$\leqslant 24$ & $29(241)$ & $15(207)$ \\
\hline $25-34$ & $52(427)$ & 38 (539) \\
\hline $35-44$ & $14(116)$ & $26(372)$ \\
\hline $45+$ & $5(43)$ & $21(294)$ \\
\hline Ethnicity & $(n=821)$ & $(n=1405)$ \\
\hline Black & $10(82)$ & $4(50)$ \\
\hline White & 85 (695) & 94 (1322) \\
\hline Asian & $4(31)$ & $1(20)$ \\
\hline Other & $2(13)$ & $1(13)$ \\
\hline Occupation class & \\
\hline |-III & \multicolumn{2}{|l|}{$\begin{array}{l}(n=818) \\
77(629)\end{array}$} \\
\hline Other & 23 (189) & NA \\
\hline Marital status & $(n=824)$ & $(n=1406)$ \\
\hline Single & $64(531)$ & $44(612)$ \\
\hline Other & $36(293)$ & $56(794)$ \\
\hline Lifetime sexual partners & \multicolumn{2}{|l|}{$(n=777)$} \\
\hline 1-9 & \multicolumn{2}{|l|}{$36(277)$} \\
\hline $10-19$ & \multicolumn{2}{|l|}{25 (191) } \\
\hline $20-49$ & \multicolumn{2}{|l|}{$24(183)$} \\
\hline $50+$ & \multicolumn{2}{|l|}{$16(126)$} \\
\hline & & $(n=1246)$ \\
\hline 0 & & $6(78)$ \\
\hline $1-4$ & & $47(588)$ \\
\hline $5-9$ & & $26(322)$ \\
\hline $10+$ & & $21(258)$ \\
\hline Age at first sexual intercourse & $(n=817)$ & $(n=1396)$ \\
\hline$\leqslant 15$ & $20(167)$ & $9(130)$ \\
\hline $16-17$ & $36(291)$ & $25(351)$ \\
\hline $18-19$ & $26(210)$ & 29 (399) \\
\hline $20+$ & 18 (149) & 31 (438) \\
\hline Not yet & $0(0)$ & $6(78)$ \\
\hline
\end{tabular}

in table 2. On univariate analysis, the prevalence of antibodies to HSV-l increased with age in both populations, HSV-1 was more common in black GUM clinic attenders than white and was less common among GUM attenders of higher socioeconomic status. Married blood donors were more likely to be infected than single.

In GUM clinic attenders, the adjusted odds of HSV-1 indicated that HSV-1 was less common among heterosexual men than women and homosexual men, became more common with increasing age and was more common among black people and those of lower socioeconomic status. Among blood donors, only increasing age and being single rather than married were independently associated with HSV-1 infection.

In relation to the behavioural factors, it is striking that early age at first intercourse is much more strongly associated with presence of HSV-1, than lifetime partners in both groups. Among GUM clinic attenders someone who was aged 20 was over $60 \%$ less likely to have HSV-1 than someone who had sex for the first time aged 15. Although the association was less marked in blood donors, those aged 20 at first intercourse were $36 \%$ less likely to have HSV-1 than those who had sex for the first time aged $\leqslant 15$.

\section{Key messages}

- HSV-1 is a common infection in adults in the UK $146 \%$ in blood donors and $60 \%$ of GUM clinic attenders are HSV-1 positive)

- This study shows that HSV-1 infection is related to sexual behaviour in that prevalence is strongly related to age at first intercourse (and to sexual orientation and sex in GUM clinic attenders)

- The association with early age at first intercourse is striking and may reflect the particular sexual practices of people initiating sex in this age group.

\section{DISCUSSION}

Population based studies of sexual behaviour confirm that the age of first sexual intercourse in Britain has decreased over the past 30 years, although this has likely stabilised over the past decade. ${ }^{10}$ Data from other studies confirm that childhood acquisition of HSV-l (presumably non-sexual) is declining and that a majority of young people are HSV-1 naive when they start to become sexually active. ${ }^{3}$ Several centres in the United Kingdom report that primary genital HSV-1 is now the most common cause of genital herpes in young women. ${ }^{4}$

In this study we demonstrate that in the United Kingdom HSV- 1 behaves similarly to some of the viral STIs, such as HSV-2 and HIV. It is more common among women and homosexual men than heterosexual men and among GUM clinic attenders than blood donors. Age of first intercourse is the strongest predictor of infection. However, serological evidence of HSV- 1 antibody provides no information about likely site of sexually acquired HSV-1. Study participants were asked about past diagnosis and symptoms of both oro-labial and genital herpes. These data have been presented elsewhere ${ }^{8}$ but in brief indicate that around $16 \%$ of GUM attenders with HSV-l antibody alone had symptoms suggestive of genital herpes but that this rate was much lower in blood donors (3\%). Sexual transmission of HSV-1 can result in oro-labial herpes (through kissing) or genital herpes (through either oro-genital or possibly genital-genital contact). However, the fact that more than $60 \%$ of genital infections in young women in some centres are due to HSV-1 means that at least some of these infections are likely to be genitally acquired. ${ }^{4}$

These data have two implications for young people. It appears that people who start having sex at an early age are particularly vulnerable to infection with HSV-1, more likely as a result of their sexual behaviour than because of any biological predisposition. Of note, because HSV-l is transmitted through both social and sexual contact, individuals who have never had sex but are infected with HSV-1 can potentially transmit genital herpes to their sexual partners. Secondly, because transmission studies have not shown that HSV-l infection is protective of acquisition of infection with HSV$2,{ }^{11}{ }^{12}$ an individual who acquires genital herpes due to HSV-1 early in life could potentially acquire infection with HSV-2 subsequently, which is more likely to become recurrent.

\section{Authors' affiliations}

F M Cowan, A Copas, A M Johnson, Department of Sexually Transmitted Diseases, Royal Free and University College Medical School, University College London, UK

R Ashley, L Corey, University of Washington, Seattle, USA

A Mindel, University of Sydney and Westmead Hospital, Sydney, Australia

Correspondence to: Dr Frances Cowan, Department of Sexually Transmitted Diseases, Royal Free and Úniversity College Medical School, Mortimer Market Centre, off Capper Street, London WC IE 6AU, UK; frances@uz-ucsf.co.zw

Accepted for publication 12 August 2002 
Table 2 Demographic and behavioural associations with HSV-1 antibody prevalence, with unadjusted odds ratios (ORs) based in all participants and adjusted ORs based on sexually active participants only

\begin{tabular}{|c|c|c|c|c|c|c|}
\hline \multirow[b]{2}{*}{ Characteristic } & \multicolumn{3}{|l|}{ GUM attenders } & \multicolumn{3}{|l|}{ Blood donors } \\
\hline & $\begin{array}{l}\text { HSV-1 } \\
\text { prevalence, } \% \\
\text { (No HSV-1 +ve) }\end{array}$ & $\begin{array}{l}\mathrm{p} \text { Value, } \\
\text { unadjusted OR }\end{array}$ & $\begin{array}{l}\mathrm{p} \text { Value, } \\
\text { adjusted } O R\end{array}$ & $\begin{array}{l}\text { HSV-1 } \\
\text { prevalence, \% } \\
\text { (No HSV-1 +ve) }\end{array}$ & $\begin{array}{l}\mathrm{p} \text { Value, } \\
\text { unadjusted OR }\end{array}$ & $\begin{array}{l}\text { p Value, } \\
\text { adjusted } O R\end{array}$ \\
\hline Sex & & & & & $p=0.35$ & $p=0.13$ \\
\hline Female & & & & $47(678)$ & $1-$ & $1-$ \\
\hline Male & & & & 45 (329) & $0.91(0.73-1.12)$ & $0.83(0.65-1.06)$ \\
\hline Sex/orientation & & $p=0.001$ & $p=0.005$ & & & \\
\hline Female & 58 (199) & $1-$ & $1-$ & & & \\
\hline Male heterosexual & 56 (162) & $0.91(0.66-1.25)$ & $0.66(0.46-0.95)$ & & & \\
\hline Male homosexual & $72(138)$ & $1.82(1.24-2.65)$ & $1.36(0.83-2.23)$ & & & \\
\hline Age* $^{*}$ & & $p<0.001$ & $p<0.001$ & & $p<0.001$ & $p<0.001$ \\
\hline$\leqslant 24$ & 53 (127) & $1-$ & $1-$ & $39(80)$ & $1-$ & $1-$ \\
\hline $25-34$ & $60(258)$ & $1.37(1.00-1.88)$ & $1.50(1.03-2.18)$ & $41(219)$ & $1.09(0.78-1.51)$ & $1.00(0.67-1.49)$ \\
\hline $35-44$ & $69(80)$ & $1.99(1.25-3.18)$ & $2.65(1.49-4.72)$ & $50(186)$ & $1.59(1.12-2.24)$ & $1.47(0.94-2.30)$ \\
\hline $45+$ & $79(34)$ & $3.39(1.57-7.38)$ & $3.61(1.43-9.14)$ & $56(166)$ & $2.06(1.43-2.96)$ & $2.07(1.27-3.39)$ \\
\hline Ethnicity & & $p=0.001$ & $P=0.001$ & & $p=0.43$ & $p=0.64$ \\
\hline White & $58(404)$ & $1-$ & $1-$ & $46(602)$ & $1-$ & $1-$ \\
\hline Black & $80(66)$ & $2.97(1.69-5.24)$ & $3.34(1.83-6.11)$ & $54(27)$ & $1.40(0.80-2.47)$ & $1.53(0.78-2.99)$ \\
\hline Asian & 58 (18) & $1.00(0.48-2.07)$ & $1.10(0.49-2.48)$ & $50(10)$ & $1.20(0.49-2.89)$ & $0.99(0.30-3.22)$ \\
\hline Other & $54(7)$ & $0.84(0.28-2.53)$ & $0.70(0.22-2.27)$ & $62(8)$ & $1.91(0.62-5.88)$ & $1.30(0.34-4.98)$ \\
\hline Occupation class & & $p=0.02$ & $p=0.05$ & & & \\
\hline |-III & $58(365)$ & $0.66(0.47-0.93)$ & $0.68(0.46-1.00)$ & & & \\
\hline Other & $68(128)$ & 1 - & $1-$ & & & \\
\hline Marital status & & $p=0.22$ & $p=0.47$ & & $p<0.001$ & $p=0.03$ \\
\hline Single & $59(312)$ & $0.83(0.62-1.12)$ & $0.88(0.63-1.24)$ & $39(240)$ & $0.61(0.49-0.76)$ & $0.73(0.55-0.97)$ \\
\hline Other & 63 (185) & $1-$ & $1-$ & 51 (408) & $1-$ & $1-$ \\
\hline Lifetime sexual partners* & & $p=0.002$ & $p=0.13$ & & & \\
\hline $1-9$ & 53 (148) & $1-$ & $1-$ & & & \\
\hline $10-19$ & $58(111)$ & $1.21(0.83-1.75)$ & $1.13(0.75-1.71)$ & & & \\
\hline $20-49$ & 55 (101) & $1.08(0.74-1.56)$ & $0.88(0.56-1.39)$ & & & \\
\hline $50+$ & 77 (97) & $2.92(1.81-4.70)$ & $1.85(1.00-3.39)$ & & & \\
\hline & & & & & $p=0.03$ & $p=0.21$ \\
\hline 0 & & & & $36(28)$ & $1-$ & - \\
\hline $1-4$ & & & & $44(260)$ & $1.42(0.87-2.31)$ & $1-$ \\
\hline $5-9$ & & & & $51(163)$ & $1.83(1.10-3.05)$ & $1.29(0.96-1.73)$ \\
\hline $10+$ & & & & 48 (123) & $1.62(0.96-2.74)$ & $1.07(0.77-1.49)$ \\
\hline Age at first sexual intercourse* & & $p=0.003$ & $p=0.003$ & & $p=0.01$ & $p=0.001$ \\
\hline$\leqslant 15$ & $72(120)$ & $1-$ & $1-$ & $50(65)$ & $1-$ & $1-$ \\
\hline $16-17$ & $58(169)$ & $0.54(0.36-0.82)$ & $0.59(0.37-0.92)$ & $51(179)$ & $1.04(0.70-1.56)$ & $0.94(0.59-1.49)$ \\
\hline $18-19$ & $56(117)$ & $0.49(0.32-0.76)$ & $0.45(0.28-0.74)$ & $45(180)$ & $0.82(0.55-1.22)$ & $0.77(0.49-1.22)$ \\
\hline $20+$ & $56(83)$ & $0.49(0.31-0.79)$ & $0.37(0.21-0.65)$ & $44(194)$ & $0.80(0.54-1.18)$ & $0.64(0.39-1.05)$ \\
\hline Not yet & - & - & - & $36(28)$ & $0.56(0.31-1.00)$ & - \\
\hline
\end{tabular}

*For these ordinal factors, statistical tests are based on the raw figures, not the grouped data. The Mann-Whitney test is used for the unadjusted testing, and the adjusted is based on the inclusion of the linear term in the logistic regression model.

\section{REFERENCES}

1 Corey L, Wald A. Genital herpes. In Holmes KK, Sparling PF, Mardh P-A, Lemon SM, Stamm WE, Piot P, et al, eds. Sexually transmitted diseases. New York: McGraw Hill, 1999:285-312.

2 Nahmias AJ, Lee FK, Beckman-Nahmias S. Sero-epidemiological and -sociological patterns of herpes simplex virus infection in the world. Scand J Infect Dis 1990.

3 Vyse A, Gay N, Slomka M, et al. The burden of infection with HSV-1 and HSV-2 in England and Wales: implications for the changing epidemiology of genital herpes. Sex Transm Infect 2000;76:183-7.

4 Ross JDC, Smith IW, Elton RA. The epidemiology of herpes simplex types 1 and 2 infection of the genital tract in Edinburgh 1978-1991. Genitourin Med 1993;69:381-3.

5 Scoular A, Leask BGS, Carrington D. Changing trends in genital herpes due to Herpes simplex virus type 1 in Glasgow, 1985-88. Genitourin Med 1990;66:226-8.

6 Rodgers CA, O'Mahony C. High prevalence of herpes simplex virus type 1 in female anogenital herpes simplex. Int J STD AIDS 1995;6:144.
7 Cowan FM, Johnson AM, Ashley R, et al. Antibody to herpes simplex virus type 2 as a serological marker of sexual lifestyle in populations. BM 1994:309:1325-9.

8 Cowan FM, Johnson AM, Ashley R, et al. Relationship between antibodies to herpes simplex virus (HSV) and symptoms of HSV infection. $J$ Infect Dis 1996;174:470-5.

9 Ashley RL, Militoni J, Lee F, et al. Comparison of western blot (immunoblot) and glycoprotein G-specific immunodot enzyme assay for detecting antibodies to herpes simplex virus types 1 and 2 in human sera. J Clin Microbiol 1988;26:662-7.

10 Wellings K, Nanchahal K, Macdowall W, et al. Sexual behaviour in Britain: early heterosexual experience. Lancet 2001;358: 1843-50.

11 Corey L, Langenberg A, Ashley RL, et al. Recombinant glycoprotein vaccine for the prevention of genital HSV-2 infections -2 randomised controlled trials. JAMA 1999;282:331-40.

12 Brown ZA, Selke S, Zeh J, et al. The acquisition of herpes simplex virus during pregnancy. N Engl J Med 1997;337:509-15 